\title{
Fuerza, forma y expresión entre los siglos XVIII y XIX
}

\author{
Force, Form and Expression between \\ XVIIIth and XIXth centuries
}

JORGE LÓPEZ LLORET*

\begin{abstract}
Resumen: En la segunda mitad del siglo XVIII Rousseau puso de moda la expresión como fundamento de la actividad filosófica. Poco después Lavater popularizó la Fisiognómica como una disciplina potencialmente universal. A finales de siglo en el entorno del Clasicismo de Weimar y del Romanticismo de Jena se comenzó a desarrollar dicho potencial en la teoría estética y literaria. En este marco los hermanos Humboldt dieron un paso más y extendieron el principio de expresión a las ciencias de la naturaleza y del espíritu. Finalmente, todas estas tendencias fueron elaboradas filosóficamente por Schopenhauer, formando una parte importante de su doctrina.

Palabras clave: forma, fuerza, expresión, Fisiognómica, prerromanticismo, Schopenhauer.
\end{abstract}

\begin{abstract}
In the second half of XVIIIth century Rousseau put into fashion the expression as the foundation of philosophical activity. Shortly after Lavater popularized the Physiognomy as a potentially universal discipline. At the end of the century in the vicinity of Classicism of Weimar and Romanticism of Jena began to develop that potential in aesthetics and literary theory. In this framework the Humboldt brothers went a step further and extended the principle of expression to nature and human sciences. Finally, all these trends were thought out philosophically by Schopenhauer, forming an important part of his doctrine.

Key words: form, force, expression, Physiognomy, Preromanticism, Schopenhauer.
\end{abstract}

\section{Introducción}

1. La Fisiognómica, que estudiaba la conexión expresiva entre el rostro de una persona y su interioridad, generó en los siglos XVIII y XIX un esquema según el cual todo lo real consistía en una dinámica interna que se expresaba en formas exteriores. Todo era forma y fuerza. ${ }^{1}$ «Forma» $\mathrm{y}$ «fuerza» fueron términos comunes en ambos siglos gracias al prestigio del modelo

Fecha de recepción: 23/06/2013. Fecha de aceptación: 02/08/2013.

* Universidad de Sevilla. Profesor Titular de Universidad. E-mail: Lopezlloret@us.es. Líneas de investigación: Historia de la Estética en los siglos XVIII y XIX; Estética del Diseño Industrial. Publicaciones recientes: «Opacidad y transparencia. El rostro como metáfora estética en la segunda mitad del siglo XVIII», Estudios Filosóficos, vol. LVIII, no 169 (2009), pp. 457-481; «Perversa segunda piel. Ética, estética y política en el vestido según Jean-Jacques Rousseau», Cuadernos Dieciochistas, 11 (2010), pp. 235-270.

1 Caro Baroja, J., Historia de la Fisiognómica, Madrid, Istmo, 1988; y Bordes, J., Historia de las teorías de la figura humana, Madrid, Cátedra, 2003, pp. 286-355. 
newtoniano. Al coexistir éste con el punto álgido del desarrollo de la Fisiognómica se unió con su principio de expresión..$^{2}$ La forma fue expresión de la fuerza, como expuso Kant en sus Principios metafísicos de la ciencia de la naturaleza. Si para Lavater la Fisiognómica se refería al ser humano y para Rousseau la expresión era personal, con el tiempo se vieron fisonomías en las plantas, las montañas, los artefactos, la experiencia estética, la historia y la cultura, hasta llegar a ser un elemento importante en un sistema filosófico como el de Schopenhauer. ${ }^{3}$

En lo que sigue nos centraremos especialmente en éste, pues en las partes II y III se tratan múltiples autores como introducción. No hacemos referencia a otros que son muy relevantes en el desarrollo de la Fisiognómica, como Goethe. Lo que hemos pretendido es preparar el terreno para el análisis de Schopenhauer, resultándonos pertinentes como inicio de líneas de desarrollo que confluyen en él.

Después de Schopenhauer no se podía ir más allá por ese camino porque las ciencias iniciaron un proceso de especialización que lo impedía. La Fisiognómica subsistió, aligerada de su carga metafísica, en la creación artística, la estética, los estudios culturales y, en menor medida, el análisis del comportamiento animal.

\section{El proceso de centralización de la expresión}

2. La de «fuerza» fue una noción central en el siglo XVIII por el papel que jugó en el sistema del mundo newtoniano. Apareció en sus Principia mathematica desde la Definición III y al final se conectó con un «espíritu sutilísimo que penetra y yace latente en todos los cuerpos». ${ }^{4}$

Según Newton a Dios «sólo le conocemos por propiedades y atributos, por las sapientísimas y óptimas estructuras de las cosas y causas finales», concluyendo que «nuestras nociones de Dios se obtienen mediante cierta analogía con las cosas humanas». ${ }^{5}$ Mostró la belleza matemática de la forma del universo, posible por la fuerza, cuyos efectos analizó minuciosamente. Indagar más allá de estos, mediante hipótesis, alejaría de la filosofía natural. Sólo cabía proceder por «analogías humanas».

En este sistema forma y fuerza estaban íntimamente unidas, como expuso Kant al afirmar que la «materia llena un espacio [...] mediante una fuerza motriz particular». Tiene fuerza «lo que ocupa un espacio». ${ }^{6}$ Sólo la materia lo ocupaba, pues fuera de la materia no podía pensarse ningún sujeto, salvo el espacio mismo. Este llenar el espacio era fuerza. La reducción del concepto de «materia» al de «fuerza motriz» hacía de la percepción un efecto de la fuerza. ${ }^{7}$

Kant no definió la noción de fuerza, pero pensaba que todo lo percibido lo era. En ocasiones habló antropomórficamente, como al decir del espacio que la fuerza expansiva «se

2 Véase Menke, Ch., Force. A fundamental Concept of Aesthetic Anthropology, New York, Fordham University Press, 2013, pp. 61-80.

3 No planteamos que esto agote los niveles de interpretación de una obra como la de Schopenhauer ni de una época como la tratada. Creemos que es un tema poco trabajado en el sentido en el que lo hacemos, integrable con otras líneas de análisis.

4 Newton, I., Principios matemáticos de la filosofía natural, Madrid, Tecnos, 1987, p. 621.

5 Ibídem, pp. 620s.

6 Kant, I., Principios metafísicos de la ciencia de la naturaleza, Madrid, Alianza, 1989, pp. 70s.

7 Ibídem, pp. 78, 72 y 106 y 108. 
esfuerza» por extenderlo. ${ }^{8}$ Este «esfuerzo» muestra que materia y fuerza son parte de algo sólo comprensible mediante analogías vitales, pues el afán es el distintivo de lo vivo: «la vida es la facultad de una sustancia de determinarse por sí misma para actuar a partir de un principio interno [...] y de una sustancia material para determinarse a sí misma en el movimiento o en el reposo». ${ }^{9}$ La materia es fuerza y cuando se auto-determina es vida. La forma de lo vivo es su resultado perceptible. Fuerza y forma se conectan según el esquema de la expresión.

3. Rousseau desarrolló dicho esquema con su teoría de la filosofía como expresión personal. ${ }^{10}$ Partió de la concepción de la naturaleza como algo que crece. La vida es desarrollo y la forma de cada ser es expresión de su dinámica interna. A partir de ahí presentó propuestas que iban de la jardinería a la educación. Por ejemplo, la belleza de un árbol no residía en una geometría impuesta, sino en las formas naturales de su crecimiento; o la educación del ser humano consistía en permitir el desarrollo de la persona según sus peculiaridades, sin imponer un modelo. ${ }^{11}$

Starobinsky definió esta filosofía como «transparencia». ${ }^{12}$ Era un ideal vital que se atenía al esquema de la expresión. Todo ser vivo busca la forma específica que lo manifieste y exprese. Rousseau radicalizó esto en Las confesiones, donde se propuso como único tema de escritura, prometiendo mostrar con la mayor honestidad posible su dinámica interna. La filosofía debía explicar la forma vital del escritor, debida a unas fuerzas interiores conocidas por introspección. ${ }^{13}$ La puso en práctica en Las ensoñaciones del paseante solitario, donde siguió el flujo de sus tensiones emocionales. ${ }^{14}$

Eso respondía a su concepción del lenguaje, originado como música y ésta como expresión de las emociones, forma perceptible que exponía las tensiones internas del ser humano..$^{15}$ Era algo extensible a todos los productos culturales. Para referirse a este esquema de la expresión Schiller usó el término «ingenuo»: lo son el escritor o la cultura que se expresan de manera inmediata en sus productos. ${ }^{16}$ Todo lo cual influyó en el entorno prerromántico al que perteneció Lavater.

4. Lavater fue uno de los mayores divulgadores de la Fisiognómica, sentando las bases para su extensión, más allá del rostro humano, a todo lo real, sustituyendo los términos «alma» o «carácter» por el más genérico de «fuerza», reduciendo el interior del ser humano

8 Ibídem, pp. 72s.

9 Ibídem, p. 133.

10 López Lloret, J., «Opacidad y transparencia. El rostro como metáfora estética en la segunda mitad del siglo XVIII», Estudios Filosóficos, vol. LVIII, no 169 (2009), pp. 457-481; y «Perversa segunda piel. Ética, estética y política en el vestido según Jean-Jacques Rousseau», Cuadernos Dieciochistas, 11 (2010), pp. 235-270.

11 Rousseau, J.-J., Julia, o la nueva Eloísa, Madrid, Akal, 2007, pp. 515-531; Rousseau, J.-J., Emilio, o de la educación, Madrid, Alianza, 2007, pp. 37-41.

12 Starobinski, J., Jean-Jacques Rousseau: la transparencia y el obstáculo, Madrid, Taurus, 1983.

13 Rousseau, J.-J., Las confesiones, Madrid, Alianza, 1997, p. 27.

14 Rousseau, J.-J., Las ensoñaciones del paseante solitario, Madrid, Alianza, 1983, p. 36.

15 Rousseau, J.-J., Ensayo sobre el origen de las lenguas, Madrid, Akal, 1980, pp. 32-34 y 83-87.

16 Schiller, F., Sobre la gracia y la dignidad. Sobre poesía ingenua y poesía sentimental, Barcelona, Icaria, 1985, pp. 67-90. 
a dinámicas internas expresadas en un exterior con una forma cada vez más definida. La forma de todas las cosas manifestaba sus fuerzas interiores.

Cotidianamente interpretamos las situaciones más comunes como expresión de fuerzas interiores porque, según Lavater: «¿no es toda la naturaleza fisiognomía? [...] ¿efecto exterior y fuerza interior?» ${ }^{17}$ Todo lo que existe es fuerza que se expresa en forma. La Fisiognómica, que lo estudia, es universal. ${ }^{18}$ Aunque su extensión se inició antes de Lavater, su universalización se debió a él, debido a su reducción de los elementos de la expresión facial a formas lineales. Reducido el rostro a línea se procedía a trazar la silueta elemental. Después se procedía al análisis: se aislaban ojos, nariz, boca, etc., trazándose sus ritmos lineales. Así se obtenía una sintaxis lineal abstracta y autónoma que se podía observar en cualquier fenómeno. ${ }^{19}$ Todo era expresión de fuerzas subyacentes que se manifestaban en diferentes formas.

5. Kant definió la Fisiognómica como «el arte de juzgar por los rasgos visibles de una persona o, en consecuencia, por lo exterior, acerca de su interior; ya se trate de su índole sensible o de la moral». ${ }^{20}$ La palabra traducida como «índole sensible» es «Sinnesart», siendo «Sinn» «sentido», «inclinación», «pensamiento», «sentimiento» o «gusto». «Índole moral» traduce «Denkungsart», también «mentalidad». ${ }^{21}$ La Fisiognómica juzgaba la compleja dinámica interior de la persona a partir de la sintaxis de sus rasgos exteriores.

Aunque rechazó ciertos tópicos de la Fisiognómica (como la conexión de belleza y bondad o fealdad y maldad y la analogía del rostro humano con el animal22), la aceptó como otra manifestación del esquema de la expresión, aplicado a la más libre de las manifestaciones vitales, el ser humano. No es que considerase que la filosofía natural y la antropología pragmática trataran de lo mismo, pero sí eran análogas como extremos de la escala del citado esquema.

Durante la década en la que se publicó la Antropología de Kant esa escala se fue diversificando en el marco de la expansión de la Fisiognómica desde el ser humano al resto de los fenómenos. Al final un kantiano confeso, Schopenhauer, afirmó que sí trataban de lo mismo.

\section{Diversificación y afinamiento del esquema fisiognómico}

6. Su expansión siguió dos direcciones. Se produjo su desarrollo, por un lado, en la estética del objeto y de la expresión del sujeto; por otro, en disciplinas científicas como la biología y el análisis cultural. Lo veremos en este orden.

Schiller, admirador de Rousseau, desarrolló su estética tras leer a Kant. Sus dos obras fundamentales, Kallias y Cartas sobre la educación estética de la humanidad, tratan del

17 Lavater, J. C., Physiognomische Fragmente, Erster Band, Winterthur, Heinrich Steiner, 1783, pp. $26-28$.

18 Lavater, J. C., Physiognomische Fragmente, Vierter Band, Winterthur, Heinrich Steiner, 1778, p. 39.

19 Sobre la silueta, Lavater, J. C., Physiognomische Fragmente, Zweyter Band, Winterthur, Heinrich Steiner, 1784, pp. 108-122; sobre el «despedazamiento»: Lavater, J. C., Physiognomische Fragmente, Dritter Band, Winterthur, Heinrich Steiner, 1777, pp. 121-130; sobre la abstracción lineal Lavater, J. C., Physiognomische Fragmente, Vierter Band, o. c., pp. 343-349.

20 Kant, I., Antropología, Madrid, Alianza, 1991, p. 242.

21 Kant, I., Anthropologie in pragmatischer hinsicht, Königsberg, Friedrich Nicolovius, 1800, p. 270.

22 Kant, I., Antropología, o. c., pp. 243-245. 
objeto y el sujeto estéticos. Dio gran importancia a la libertad como auto-manifestación, dinámica interior que se daba su forma exterior, enfocando así sus dos campos de estudio según el esquema de la expresión.

En Kallias ahondó en la Fisiognómica abstracta de la sintaxis lineal. Tratando la belleza del objeto como «libertad en la apariencia» recurrió a la línea ondulada estudiada por Hogarth. ${ }^{23}$ Para Schiller era hermosa por su dinamismo. Toda línea era la forma visual que expresaba una dinámica interior. ${ }^{24} \mathrm{Al}$ ver un objeto, para nosotros compuesto de líneas, proyectamos en él nuestra experiencia corporal, lo asimilamos como a la línea que siguen nuestros pasos movidos por nuestra voluntad. En todo objeto hay dinámica interna y forma que la expresa; ésta anticipa hipótesis de fuerzas interiores, como hacemos con las personas.

En Sobre gracia y dignidad y en Cartas sobre la educación estética del hombre, cuyos temas eran la actitud ética y la subjetividad humana, utilizó el mismo esquema. Este funcionaba en la ética de la gracia, referida a un comportamiento en el que la acción expresa la condición del agente. ${ }^{25}$ Como en la estética del objeto, la acción es tan concreta que brota de cada sujeto. De aquí surgió la condición antropológica de las Cartas, consistente en «exteriorizar lo interno y dar forma a lo externo» a través de dos manifestaciones de la fuerza, el «impulso sensible», que encarna al sujeto en el mundo, y el «impulso formal», que lo dota de una forma que lo expresa. ${ }^{26} \mathrm{El}$ ser humano es también una combinación peculiar de fuerza y forma. ${ }^{27}$ Mediante la experiencia estética Schiller dio un paso en la universalización de la Fisiognómica. ${ }^{28}$

7. Los románticos de Jena extendieron las ideas de Rousseau en el ámbito literario y desde él lo ampliaron a todo lo real.

Friedrich Schlegel afirmó que la poesía moderna se basaba en lo característico, desplazando el orden clásico frente a la forma como expresión. ${ }^{29}$ Aunque eso se refería a la poética, tuvo consecuencias para la concepción del sujeto creador tras sus reflexiones sobre la novela. ${ }^{30} \mathrm{Su}$ tesis era que la literatura moderna surgía de la necesidad expresiva del creador, plasmando en la forma escrita la fuerza que es el sujeto. ${ }^{31}$ Aplicaba la dinámica de la subjetividad de Fichte a la idea del lenguaje de Rousseau, lo que le llevó a buscar alternativas a lo clásico (como lo medieval) y al estudio de lo «árabe» y la teoría del arabesco, motivo construido sin modelo que surgía del impulso del sujeto, que con él se daba su forma. ${ }^{32}$

23 Schiller, F., Kallias. Cartas sobre la educación estética del hombre, Barcelona, Anthropos, 1990, pp. $43-87$.

24 Ibídem, pp. 83-87.

25 Schiller, F., Sobre la gracia y la dignidad. Sobre poesía ingenua y poesía sentimental, o. c., pp. 9-47.

26 Schiller, F., Kallias. Cartas sobre la educación estética del hombre, o. c., p. 199.

27 Ibídem, p. 363.

28 Sobre Schiller y la Fisiognómica véase Beiser, F., Schiller as Philosopher. A Re-Examination, Oxford, Oxford University Press, 2005, pp. 97-100.

29 Schlegel, F., Sobre el estudio de la poesía griega, Madrid, Akal, 1996, pp. 51-65.

30 Schlegel, F., Poesía y filosofía, Madrid, Alianza, 1994, pp. 95-149.

31 Ibídem, o.c., p. 118s.

32 Ibídem, pp. 131-138. 
Schlegel comparó el surgimiento de la forma literaria a partir de la fuerza humana con el de la naturaleza a partir del núcleo terrestre. ${ }^{33}$ Ambos casos son dinamismo que se expresa en forma. Esto lo desarrolló Novalis, dejándolo en el punto en el que estaban trabajando los hermanos Humboldt.

8. Para Novalis todo era signatura. ${ }^{34}$ Esto aconsejaba basar la geognosia en el lenguaje..$^{35}$ El lenguaje era metáfora de un espíritu del mundo que se señalaba dando forma a la materia, una fuerza vocal universal que al encarnarse en ésta generaba las signaturas. La relación entre forma y fuerza era de esquematización, la materia era el esquema de la fuerza. ${ }^{36}$ Esta es dinámica pura y aquélla su modulación formal. El movimiento puro es el espíritu, definido por Novalis, en clave fichteana, como acción que en el cuerpo adquiere figura por la luz, el aire y el calor, tres de los elementos fundamentales de la ecología de Alexander von Humboldt. ${ }^{37}$

La relación expresiva la desarrolló con su teoría de la «secreción», una analogía hormonal: lo secretado es producido por el organismo desde dentro, como lo vivo es secretado por la vida, fuerza que produce formas corporales y espirituales. ${ }^{38}$ Todas las formas expresan la vida. Con el concepto de secreción Novalis unió la fuerza y la forma en el esquema de la expresión. Aceptando el simbolismo de la naturaleza como un gran animal cuyo interior (fuerza) se daba su forma compleja, interpretó la individualidad de cada fenómeno como un rasgo formal de la dinámica básica. ${ }^{39}$ Así se podía «leer» en la forma la personalidad de cada región terrestre. Esto nos conduce a las ideas de los Humboldt en torno a la Fisiognómica del paisaje y la historia.

9. En el entorno de Goethe y Schiller la Fisiognómica gozó de gran predicamento. A este ámbito pertenecieron los Humboldt, que convivieron con el Romanticismo de Jena. Ambos aceptaron la Fisiognómica y la ampliaron. Wilhelm estuvo tan familiarizado que al viajar veía el mundo desde ella, como en sus descripciones de España. En sus retratos buscaba lo característico en las personas, los animales y los paisajes, coincidiendo con su hermano. Lo más interesante fue su extensión a la cultura y la historia..$^{40}$

En Sobre la diversidad de la estructura del lenguaje humano comparó el lenguaje con el rostro humano. ${ }^{41}$ Recurrió a la Fisiognómica para ilustrar la conexión de la palabra y el concepto. ${ }^{42}$ Diferenció entre interior y exterior en el lenguaje, relacionándolos según el esquema expresivo. Lo interior es conceptual y emocional, siempre en proceso de

33 Ibídem, p. 96.

34 Novalis, La enciclopedia, Madrid, Espiral, 1996, p. 135.

35 Ibídem, p. 238.

36 Ibídem, p. 146.

37 Ibídem, p. 213.

38 Ibídem, pp. 248 y 316.

39 Ibídem, pp. 249 y 255.

40 Von Humboldt, W., Diario del viaje a España, 1799-1800, Madrid, Cátedra, 1998, pp. 49, 50, 59, 70, 139, 143, 155-157., 169s., 172 o 224s., entre muchos ejemplos.

41 Von Humboldt, W., Sobre la diversidad de la estructura del lenguaje humano, Barcelona, Anthropos, 1990, p. 67.

42 Ibídem, p. 132. 
exposición en la forma exterior, que lo aclara sin agotarlo. Si ésta se fija demasiado la fuerza interior es coartada. Por eso el lenguaje se expresa en formas cambiantes. Se acercó a Novalis al considerar el lenguaje una emanación espontánea del espíritu; ${ }^{43}$ también a Fichte al proponer al alma como fuerza activa en la base de todas las operaciones en las que se expresaba. ${ }^{44} \mathrm{La}$ lucha de esta fuerza por darse forma define la naturaleza histórica del lenguaje. La aplicación de la Fisiognómica al estudio estructural e histórico del lenguaje la situó como el eje de la historia.

En Los límites de la acción del Estado trazó las relaciones entre sujeto y sociedad. La individualidad que limita la acción del Estado es un conjunto de fuerzas activas que se deben formalizar bajo una dominante que define su carácter. ${ }^{45}$ Estas fuerzas que surgen del interior del individuo no se deben dirigir desde fuera. ${ }^{46}$ Pues la fuerza define los derechos individuales, el Estado no debe interferir en su expresión. ${ }^{47} \mathrm{El}$ individuo es feliz cuando sus fuerzas corporales y espirituales se armonizan en una forma que las exprese a todas, lo que consiguieron los griegos, que por ello le sirvieron de modelo. ${ }^{48}$ Lo sensible es la envoltura que expresa lo espiritual, que es el principio vivificante de la forma.49

La fundamentación de la propiedad, la educación, la justicia, la economía y la política en esta libertad define el sentido de la historia: el desarrollo de las fuerzas individuales en unas formas socio-políticas en las que dominan unas u otras, lo que marca la fisonomía de cada época. La tarea del historiador es aclarar el nexo de las formas históricas con sus fuerzas de origen, haciéndolo por introspección, yendo del conocimiento de sí mismo a la historia.$^{50} \mathrm{El}$ historiador es un fisonomista de las sociedades y la Historia una forma de Fisiognómica.

En 1796 desarrolló la idea de que el género humano es un todo cuyas partes son los individuos, que «se aproximan a un fin común por medio de la formación de sus diversas fuerzas conforme a un plan». ${ }^{51}$ Aunque cada época posee peculiaridad fisiognómica, todas expresan una fuerza común. ${ }^{52}$

Una de sus ideas sobre «la tarea del historiador» nos permite resumir su aproximación fisiognómica a la historia:

«La exposición histórica [...] puede suceder por un doble camino: mediante la copia inmediata de los contornos exteriores tan exactamente como sean capaces el ojo y la mano; o desde dentro hacia afuera, mediante el estudio previo de la manera en que los contornos exteriores surgen a partir del concepto y de la forma del todo [...] el

43 Ibídem, pp. 28 y 182s.

44 Ibídem, p. 78.

45 Véase Giacomoni, P., Formazione e Transformazione. «Forza»e «Bildung» in Wilhelm von Humboldt e la sua época, Milano, Franco Angeli, 1988.

46 Von Humboldt, W., Los límites de la acción del Estado, Madrid, Tecnos, 1988, p. 18.

47 Ibídem, pp. 24 y 95.

48 Humboldt, W., Historia de la decadencia y el ocaso de los Estados libres griegos, Madrid, CSIC, 2010, pp. 71 y 121 .

49 Von Humboldt, W., Los límites de la acción del Estado, o. c., p. 99.

50 Von Humboldt, W., Escritos de filosofía de la historia, Madrid, Tecnos, 1997, p. 9.

51 Ibídem, p. 19.

52 Ibídem, pp. 23s. 
mayor mérito de la obra de arte consiste en hacer manifiesta la verdad interior de las figuras [...] tiene que sumarse, como factor tercero y conector, la expresión del alma, de la vida espiritual».53

Humboldt utilizó la Fisiognómica en el trabajo histórico y el análisis cultural. ${ }^{54}$ Ella le permitió comprender al individuo, la sociedad y la historia como un problema de conjunción de fuerzas interiores que se expresaban en una forma exterior característica. No pensaba que esta conjunción de fuerza y forma se limitara al ser humano, coincidiendo con Lavater en que eso sucedía en «el ser humano igual que las plantas». ${ }^{55}$ Afirmó que «el ser humano es una planta natural», como todos los animales..$^{56} \mathrm{Su}$ hermano Alexander extendió este modelo fisiognómico a la totalidad del cosmos físico.

10. Alexander von Humboldt incluyó en Cuadros de la naturaleza el capítulo «De la fisonomía de las plantas», extendiendo la Fisiognómica a las ciencias de la naturaleza. ${ }^{57}$ Diferenció la botánica sistemática de Linneo de la descripción fisiognómica de las peculiaridades visuales que daban «individualidad a los vegetales y, por lo tanto, al paisaje». ${ }^{58}$ Como la Fisiognómica humana estudia el rostro sin remitirse a su anatomía profunda, la de las plantas remite a lo visto..$^{59}$ En su Ensayo sobre la geografía de las plantas distinguió fisonomías vegetales individuales y colectivas.$^{60}$ En los trópicos proliferan las primeras, que se mezclan dando a sus bosques una peculiar riqueza; en las zonas templadas las formas sociales, con bosques más uniformes. Definió quince grupos fisonómicos según sus elementos característicos, algo que desarrolló después en «De la fisonomía de las plantas».61

El fisonomista de las plantas se basa en el esquema expresivo de fuerza y forma, interpretando cada forma vegetal como el resultado de una fuerza interior, la cantidad de vida que la forja ${ }^{62}$ Humboldt no pertenecía a la Naturphilosophie porque pensaba esta «cantidad» medible como presión, humedad, temperatura, altura, altitud, latitud, horas de sol, fuerza de las corrientes, pluviosidad... Estos factores marcan la cantidad y calidad del alimento y éstas la especificidad de la forma desde los polos al ecuador: «La naturaleza duerme periódicamente bajo la zona glacial porque la fluidez es la condición de la vida [...] Cuanto más se ve aumentar, aproximándose a los trópicos, la variedad de las formas, la gracia de los contornos y la combinación de los colores, tanto más se siente la fuerza y eterna juventud de la vida orgánica». ${ }^{63}$

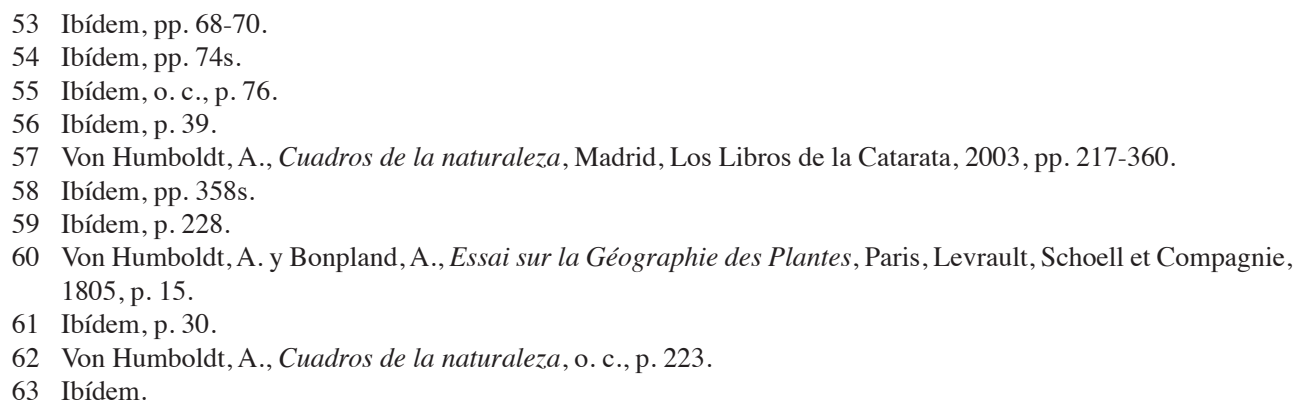


Los seres vivos se componen de fluidos en movimiento que producen su forma. Ciertas condiciones, como la humedad o el calor, favorecen esa fluxión, aumentando la cantidad de vida. Cada vegetal, su número y variedad expresan la riqueza dinámica del lugar; hay que ir de la planta al paisaje: «Del predominio de ciertas familias es de lo que depende el carácter del paisaje, el aspecto salvaje, risueño o majestuoso de la naturaleza» ${ }^{64}$ El naturalista debe estudiar la fisonomía de cada comarca, comprendiendo estética y científicamente su especificidad. ${ }^{65}$

Dando un paso más extendió, como su hermano, la Fisiognómica a la cultura. La fisonomía de cada entorno define el tono sentimental del individuo y la sociedad mediante la experiencia estética. ${ }^{66}$ Por su arraigo en un determinado entorno las sociedades tienen una fisonomía concreta, que surge por sintonía con aquél:

«[... el hombre sensible a la belleza de la naturaleza hallará aquí la explicación de la influencia que ejerce sobre el gusto y la imaginación de los pueblos. Se complacerá en examinar lo que se llama el carácter de la vegetación y la variedad de los efectos que causa en el alma del observador [...] Sólo contemplar la naturaleza, sus campos y bosques, causa un placer esencialmente diferente de la impresión que produce el estudio de la estructura específica de un ser organizado [...] es la pintura del conjunto lo que excita nuestra imaginación». ${ }^{67}$

Humboldt fue un ecólogo sistemático preocupado por la naturaleza y las sociedades asentadas en ella. Se ocupó de: geografía física, historia natural, geografía política, historia y economía, integrándolo todo en parte gracias a la Fisiognómica. La temperatura, la humedad, la presión, la altura o el suelo definen el carácter de las plantas, los animales y el entorno y todo ello el de las culturas que surgen de la zona, ${ }^{68}$ prolongando su análisis de los ecosistemas naturales hacia la cultura ${ }^{69}$ Como parte de su proyecto de estudio integral de las culturas en conexión con su suelo introdujo la Fisiognómica de los productos humanos, entre ellos el lenguaje, donde entroncó de nuevo con su hermano..$^{70}$ Esta organización fisiognómica de lo real llegó a su máxima expansión en Cosmos. Más allá no se podía ir por la vía física, aunque sí por la metafísica, transitada por Schopenhauer.

En la definición de la tarea de una «descripción física del mundo» Humboldt afirmó: «la contemplación de las cosas creadas, como unidas entre sí y formando un todo animado

64 Ibídem, p. 290.

65 Ibídem, p. 225.

66 Ibídem, p. 227.

67 Von Humboldt, A., y Bonpland, A., o. c., pp. 30s. (traducción nuestra). Esto lo analizó Humboldt en la relación histórica del su viaje a América del Sur, especialmente en von Humboldt, A., y Bonpland, A., Voyage de Humboldt et Bonpland. Première Partie. Relation Historique. Tome Second, Paris, N. Maze, 1819, capítulos XIX-XXIV, pp. 231-718.

68 Von Humboldt, A., Vistas de las cordilleras y monumentos de los pueblos indígenas de América, Madrid, Los libros de la Catarata, 2010, pp. 57 y 82.

69 Ibídem, p. 171.

70 Ibídem, pp. 52 y 275. 
por fuerzas interiores, da un carácter particular a la ciencia que tratamos en esta obra». ${ }^{71}$ No basta con la descripción de lo exterior y su sintaxis, hay que plantear un principio interior de unión: la fuerza. Con ella las meras correlaciones se vuelven carácter, algo usual tanto en la anatomía del entorno de Cuvier como en la estética del primer Romanticismo.

La sintaxis exterior animada por fuerzas interiores se convierte en expresión y, con ello, sus elementos se vuelven «rasgos característicos». ${ }^{72}$ Las fuerzas volcadas en el carácter del paisaje resuenan en el interior humano y en él se hacen estado de ánimo que, a su vez, se exterioriza en el paisaje. ${ }^{73}$ Con ello distintas variables (el sistema planetario newtoniano, la botánica descriptiva del Setecientos, la geología romántica, la anatomía comparada decimonónica o la naciente meteorología) se unen entre sí como diversas maneras en las que se manifiesta la fuerza, también expresada en la conexión de tales formas con los estados de ánimo del sujeto, produciéndose lo sublime, lo pintoresco y lo bello. ${ }^{74}$ Esa unidad era posible al «reconocer en el Universo la acción de una sola fuerza motriz que penetra la materia, la transforma y vivifica». ${ }^{75}$

Humboldt desarrolló estudios especializados que quiso conectar entre sí. Esta conexión, que hizo de la ciencia algo significativo para el ser humano, la logró con la unión expresiva de la fuerza y la forma. Recogió la herencia newtoniana y la prolongó en la emoción estética y la historia de la cultura, estudiadas por el primer Romanticismo y por su hermano Wilhelm.

Los planteamientos estudiados hasta aquí tenían que derivar en una visión filosófica de la realidad. Llegaron a su máximo desarrollo y elaboración conceptual con los dos pilares de la filosofía de Schopenhauer, la voluntad y la representación.

\section{La apoteosis del esquema}

11. Para Schopenhauer la Fisiognómica era apriorística: «es un presupuesto cuyo apriorismo y, por consiguiente, seguridad, se manifiesta en la codicia general, que surge a cada oportunidad, de ver a un hombre que ha destacado». ${ }^{76}$ Era casi una ley natural, ${ }^{77}$ una relación esencial, pues el cuerpo no era una prenda cambiable. Esta ley podía llevarse más allá del ser humano con la idea de que el rostro era el monograma de su interior. La noción de monograma indica la vía de universalización de la fuerza, la forma y su conexión fisiognómica.

En los complementos a El mundo como voluntad y representación planteó una relación entre la cosa en sí y su manifestación en el mundo de los fenómenos estructuralmente idéntica a la vista para el rostro: «este mundo, precisamente como fenómeno, es la manifestación de [...] la cosa en sí. Por eso, ésta tiene que expresar su esencia y su carácter en

71 Von Humboldt, A., Cosmos, o ensayo de una descripción física del mundo, Tomo I, Madrid, Ramón Rodríguez de Rivera, 1851, p. 58.

72 Ibídem, p. 28.

73 Ibídem, pp. 20s.

74 Ibídem, p. 38.

75 Ibídem, p. 77.

76 Schopenhauer, A., «Zur Physiognomik», en Schopenhauer, A., Parerga und Paralipomena, Zweiter Band, Berlin, A. W. Hayn, 1851, p. 509 (traducción castellana en Schopenhauer, A., Parerga y paralipómena, Madrid, Valdemar, 2009, p. 1091). Véase Lips, P., Schopenhauer und die Physiognomik, Hamburg, Hansischer Gildenverl, 1940.

77 Schopenhauer, A., Parerga und Paralipomena, o. c., p. 512 (traducción citada, p. 1094). 
el mundo de la experiencia [...] Este contenido es lo metafísico, es decir, lo que se oculta tras el disfraz del fenómeno y se cubre con sus formas». ${ }^{78}$ Esto permite plantear el esquema como monograma: «El conjunto de la experiencia se parece a una escritura secreta, y la filosofía sería su desciframiento, cuya exactitud se confirma por la conexión de todas las partes. Sólo con que este conjunto se comprenda con suficiente profundidad y la experiencia interna se combine con la externa, será posible interpretarlo y explicarlo desde sí mismo». ${ }^{79}$ Toda representación es una escritura secreta que hay que descifrar y remitir al interior no perceptible, la cosa en sí.

A ésta se llega por un proceso sobre el que el esquema fisiognómico puede arrojar luz. Al estudiar la noción de fuerza Schopenhauer afirmó la identidad de nuestro cuerpo y nuestra voluntad; aquél era el único objeto que conocemos desde fuera y desde dentro, en el que experimentamos sin mediación la conexión de la forma exterior con la dinámica interior. ${ }^{80}$ Por eso el autoconocimiento es la clave interpretativa del resto del mundo. Tanto la morfología de las cosas como la etiología de sus comportamientos se nos aparecían como monogramas porque los veíamos desde fuera. Así la fuerza «tendría que quedar inexplicada». ${ }^{81}$ Pero Schopenhauer proporcionó una clave interpretativa: «El conocimiento que tenemos de la esencia y del obrar de nuestro propio cuerpo». ${ }^{82}$

La Fisiognómica se basa en la interpretación de la conexión expresiva entre el interior y el exterior de la persona, siendo éste su monograma. La clave de su lectura (el conocimiento que tenemos de la conexión de nuestro cuerpo con sus impulsos) la extendemos a los demás seres humanos y a todas las formas representadas. Toda representación es el rostro en el que se expresa la voluntad universal. Por eso aplicó este esquema a las ciencias (de la naturaleza y del espíritu), asumiendo el legado que hemos expuesto. ${ }^{83}$

Identificó fuerza y voluntad en varios lugares. En Sobre la voluntad en la naturaleza afirmó que no cabía «concebir despliegue de fuerza, sin voluntad». ${ }^{84}$ Llegó a esto en parte mediante la extensión de la Fisiognómica: «Ninguna parte de mi doctrina podía yo esperar que recibiese menos confirmación de las ciencias empíricas que la que aplica a la naturaleza inorgánica la verdad fundamental de que la cosa en sí de Kant es la voluntad, presentándonos lo que obra en sus fuerzas todas elementales como idéntico a lo que en nosotros conocemos como voluntad». ${ }^{85} \mathrm{En}$ El mundo como voluntad y representación desarrolló la conexión

78 Schopenhauer, A., Die Welt als Wille und Vorstellung, Zweiter Band, Leipzig, F. A. Brockhaus, 1859, p. 204 (traducción castellana en Schopenhauer, A., El mundo como voluntad y representación, Madrid, Akal, 2005, p. 625).

79 Ibídem, pp. 202s. (traducción citada, p. 623).

80 Schopenhauer, A., Die Welt als Wille und Vorstellung, Erster Band, Leipzig, F. A. Brockhaus, 1859, pp. 121123 (traducción castellana en Schopenhauer, A., El mundo como voluntad y representación, Madrid, Akal, 2005, pp. 130s.).

81 Ibídem, pp. 115-117 (traducción citada, pp. 125s.).

82 Ibídem, p. 125 (traducción citada, p. 133). Véase Atwell, J. E., Schopenhauer on the Character of the World: The Metaphysics of Will, London, University of California Press, 1995, pp. 81-128.

83 Véase Atwell, J. E., o. c., pp. 53-80 y Maceiras Fafian, M., «La voluntad como energía», en Anales del Seminario de Metafísica 23 (1989), pp. 119-134.

84 Schopenhauer, A., Ueber den Willen in der natur, Frankfurt am Main, Siegmund Schmerber, 1836, p. 84 (traducción castellana en Schopenhauer, A., Sobre la voluntad en la naturaleza, Madrid, Alianza, 1987, p. 133).

85 Ibídem, p. 81 (traducción citada p. 130). 
expresiva de fuerza y forma en la física y la mecánica. ${ }^{86}$ También extendió la Fisiognómica a la morfología y fisiología animal y vegetal. La conexión entre la forma de los animales y plantas y la fuerza vital que se manifiesta en ella es de expresión: «Examínese las innumerables figuras de los animales para ver cómo no es, en todo caso, cada una de ellas nada más que la imagen de su voluntad, la expresión sensible de sus tendencias volitivas». ${ }^{87}$

El matiz fisiognómico de esto es evidente en El mundo como voluntad y representación, donde afirmó una gradación de individuación entre la naturaleza mineral, animal y humana; en el ser humano la individualidad puede mucho, en las rocas nada y en los animales puede más lo específico. En el caso humano la fisonomía es individual; en el caso de los demás animales hay una gradación, predominando progresivamente la fisonomía de la especie sobre la individual: «Esta individualidad no la tiene ni con mucho ningún animal en un grado semejante; tan sólo los animales superiores tienen un asomo de ella, sobre el que sin embargo predomina aún por completo el carácter de la especie, por lo que su fisonomía individual es escasa. Cuanto más se desciende, más se pierde toda huella del carácter individual en el carácter general de las especies; únicamente la fisonomía de estas queda». ${ }^{88}$ Esto se extiende a las plantas: «la ingenuidad con que toda planta expresa y expone abiertamente todo su carácter mediante la mera forma, revelando todo su ser y volición [...] hace que las fisonomías de las plantas sean tan interesantes». ${ }^{89}$ La planta es más interesante que el animal y éste que el humano porque tiene menos posibilidad de disimulo en la conexión expresiva de la fuerza con la forma.

Aquí se ve la conexión con Rousseau y Humboldt. Lo que para aquél era una analogía, según la cual el ser humano debía crecer como los árboles, fue invertido por Humboldt al extender la Fisiognómica a la botánica. Schopenhauer lo aplicó a la totalidad de las ciencias de la naturaleza, estableciendo una doble gradación: 1) de individualidad, desde el ser humano a las rocas, lo que no concede al ser humano la exclusiva de la expresión fisiognómica, sino sólo de la individual, pues los grados inferiores poseen fisonomía específica; 2) de transparencia: mientras menos individual más ingenua es la conexión fisiognómica, menos deformada por el disimulo. Con ello se extiende a toda la creación la Fisiognómica de las plantas de Humboldt. Para las ciencias de la naturaleza todo es fuerza expresada en forma: «No sólo en aquellos fenómenos que se parecen mucho al suyo propio, en hombres y animales, reconocerá como su esencia más interna esa misma voluntad, sino que en una reflexión sostenida le llevará a reconocer la fuerza por la cual el cristal cristaliza, la que orienta el imán hacia el Polo Norte, aquella que se le manifiesta como una descarga en el contacto de metales heterogéneos, la que en las afinidades electivas de la materia se manifiesta como huida y búsqueda, separación y reunión, y por último incluso la gravedad, que tan poderosamente afecta a toda materia»..$^{90}$

Schopenhauer también extendió la Fisiognómica a la cultura, yendo del rostro a añadidos estilísticos como el peinado, el vestido o los objetos del entorno: muebles, carruajes, obras

86 Schopenhauer, A., Die Welt als Wille und Vorstellung, Erster Band, o. c., pp. 142 (traducción citada, p. 148).

87 Schopenhauer, A., Ueber den Willen in der natur, o. c., p. 52 (traducción citada, pp. 90s.)

88 Schopenhauer, A., Die Welt als Wille und Vorstellung, Erster Band, o. c., p. 156 (traducción citada, p. 160).

89 Ibídem, p. 186 (traducción citada, p. 185).

90 Ibídem, p. 131 (traducción citada, p. 138). 
de arquitectura, incluso a la literatura y la música, también a la unión de todas ellas. ${ }^{91}$ Cada época posee su fisonomía y la Historia, a partir de su «rostro», interpreta las fuerzas que la producen..$^{22}$ Lo que se lee en esos sucesos es la dinámica de la voluntad.

En cuanto a las formas más altas de la cultura, basta con que consideremos sus extremos, la arquitectura y la música. La primera se introduce con la siguiente observación: «los objetos artificiales sirven para la expresión de las ideas, pero no sólo es la idea del objeto artificial la que habla desde ellos, sino también la idea del material». ${ }^{93} \mathrm{La}$ «idea» es la estructura pura de lo que se manifiesta y el arte su conocimiento porque depura las relaciones de los objetos. ${ }^{94}$ En el objeto arquitectónico hay dos niveles de relación: una idea de carga, ergonomía y proporción, una purificación de sus aspectos funcionales; y un material cuyas fuerzas el buen arquitecto conoce y trabaja. Por incorporarse de un modo tan patente a la fisonomía de una época la arquitectura es la disciplina más significativa para el historiador.

La fisiognómica de la arquitectura no se basa en una imitación del rostro humano, sino en que consta, como él, de formas que expresan la fuerza que las hace posibles. Para explicarla como arte Schopenhauer se centró en su material, cuyo propósito es «facilitar la clara intuición de algunas de aquellas ideas que son los grados inferiores de objetividad de la voluntad, a saber, la gravedad, la cohesión, la rigidez, la dureza, esas propiedades universales de la piedra, esas primeras y más simples y apagadas manifestaciones visibles de la voluntad».95 Su forma expresa la fuerza a la que vence, la condición de posibilidad negativa de su existencia: «la arquitectura no obra matemáticamente, sino dinámicamente [...] lo que en ella se expresa no es la forma y la simetría, sino esas fuerzas fundamentales de la naturaleza». ${ }^{96} \mathrm{La}$ arquitectura permite intuir la fisonomía de las fuerzas naturales que operan en su material y determinan su forma. Los Ordenes son el «rostro» en el que se expresa la fuerza de la gravedad según un tipo de piedra ${ }^{97}$ En la arquitectura todo es fuerza expresada en forma.

Esto se hace conocimiento puro en la música, ${ }^{98}$ que no reproduce las ideas sino «la voluntad misma», ${ }^{99}$ «capaz de expresar por sus propios medios cualquier movimiento» suyo. ${ }^{100}$ En ella el valor de la composición supera al de la ejecución, siendo a la vez expresión de la voluntad y un constructo compuesto según reglas. Afirmó la insuficiencia de la definición leibniciana de la música como aritmética porque «las relaciones numéricas en las que se resuelve no son lo significado, sino sólo el signo». ${ }^{101} \mathrm{Su}$ forma matemática resulta de la dinámica interior de la voluntad que se expresa en ella según una serie de analogías: la armonía equivale a la naturaleza inorgánica «de la que todo surge»; las voces intermedias

91 Schopenhauer, A., Parerga und Paralipomena, o. c., pp. 372s. (traducción citada, pp. 936s.).

92 Schopenhauer, A., Die Welt als Wille und Vorstellung, Erster Band, p. 215 (traducción citada, p. 210).

93 Ibídem, p. 249 (traducción citada, p. 238). Véase Schwarzer, M., «Schopenhauer’s philosophy of architecture», en Jacquette, D. (ed.), Schopenhauer, philosophy, and the arts, Cambridge, Cambridge University Press, 2007, pp. 277-298.

94 Schopenhauer, A., Die Welt als Wille und Vorstellung, Zweiter Band, o. c., pp. 413s. (traducción citada, p. 803).

95 Schopenhauer, A., Die Welt als Wille und Vorstellung, Erster Band, o. c., p. 252 (traducción citada, p. 241).

96 Ibídem, p. 254 (traducción citada, p. 243).

97 Schopenhauer, A., Die Welt als Wille und Vorstellung, Zweiter Band, o. c., p. 469 (traducción citada, p. 853).

98 Véase Ferrara, L., «Schopenhauer on music as the embodiment of Will», en Jacquette, D. (ed.), o. c., pp. $183-199$.

99 Schopenhauer, A., Die Welt als Wille und Vorstellung, Erster Band, o. c., p. 304 (traducción citada, p. 284).

100 Schopenhauer, A., Die Welt als Wille und Vorstellung, Zweiter Band, o. c., p. 512 (traducción citada, p. 889).

101 Schopenhauer, A., Die Welt als Wille und Vorstellung, Erster Band, o. c., p. 302 (traducción citada, p. 282). 
a la serie de las ideas en las que la voluntad se objetiva: las notas más cerca del bajo a los grados inferiores y las más agudas a las plantas y los animales. La melodía era «el grado más elevado de objetivación de la voluntad, la vida reflexiva y la aspiración del hombre». ${ }^{102}$ La música purificaba la relación global de la fuerza y la forma.

En cada grado expresivo estaba presente la Fisiognómica. La música, su transposición a conocimiento puro, hace transparente la dinámica de la voluntad en la forma sonora. Esta transposición muestra que, por ser su análogo purificado, la música se basa en la Fisiognómica y que la realidad es, como aquélla, una construcción en la que se modula y expresa la fuerza que lo produce todo, la voluntad.

En la metafísica de Schopenhauer se integraron elementos de origen fisiognómico. La base de la representación formal es el principio de individuación (espacio, tiempo y causalidad). La voluntad es la Fuerza que sustenta al ser. Ambas se conectan según el principio de la expresión, pues la representación manifiesta la voluntad. Su filosofía se basa en tres puntos fundamentales: que el mundo es representación (objeto para un sujeto en el espacio, el tiempo y la causalidad); que es voluntad (tendencia constante por ser); y que ésta es ontológicamente previa (la representación la objetiva). Al mundo como representación-quemanifiesta-la-voluntad se llega cuando el sujeto, comprendido como voluntad, identifica a ésta con su cuerpo y, con ello, interpreta toda representación como expresión formal de la voluntad, vivida como la «identidad esencial de todas las fuerzas que impulsan y actúan en la naturaleza». ${ }^{103} \mathrm{Su}$ filosofía se basó, pues, en la forma, la fuerza y su conexión expresiva, integrando brillantemente materiales que habían ido surgiendo a mediados del siglo XVIII en ámbitos como la antropología, la estética, la historia o las ciencias naturales. No se podía ir más allá. Aunque la Fisiognómica no perdió vigencia tras su obra, se parceló de nuevo.

\section{Conclusiones}

12. La evolución de las nociones de fuerza y forma y su conexión expresiva fue tan importante en el periodo de tiempo seleccionado que fue desarrollada en diversos ámbitos. Hemos pretendido apuntar la coherencia de su desarrollo. Comenzando con la primacía de la expresión en Rousseau, la vulgarización de la Fisiognómica por Lavater y los resquicios que la noción de fuerza introducía en el sistema del mundo newtoniano, lo hemos seguido en la estética del objeto (Schiller) y del sujeto (Romanticismo de Jena), en la ecología (Alexander von Humboldt) y las humanidades (Wilhelm von Humboldt). El proceso de expansión concluyó con su integración en la filosofía de Schopenhauer.

Tras esto el esquema expresivo no fue abandonado, pero sí acotado. Aparte del estudio del rostro, desarrollado por la cinésica, en la creación literaria y plástica fue importante, como mostraron Wechsler o Gombrich. ${ }^{104}$ En el análisis de la historia y la cultura lo mantuvieron autores como Wölfflin, Simmel o Spengler; el primero usó el esquema del esfuerzo corporal para comprender formalmente los estilos artísticos; el segundo aplicó, en su estudio de los significados sociales, formas que integraban significantes que manifestaban dinámi-

102 Ibídem, pp. 305s. (traducción citada, pp. 284s.).

103 Ibídem, p. 132 (traducción citada, p. 139).

104 Wechsler, J., A Human Comedy. Physiognomy and Caricature in 19th Century Paris, London, Thames and Hudson, 1982; Gombrich, E., Meditaciones sobre un caballo de juguete, Madrid, Debate, 1998, pp. 143-150. 
cas internas, partiendo del estudio del rostro; el tercero hizo de la Fisiognómica una noción central en la organización de la Historia. ${ }^{105}$ En el caso de las ciencias de la naturaleza tuvo desarrollos como la aproximación a la geología de Carus (contemporáneo de los Humboldt) o el estudio de la expresión animal desde Darwin hasta Lorenz, aunque el asentamiento de metodologías científicas basadas en la fórmula y el experimento redujo su importancia. ${ }^{106}$

Hay dos cosas en el siglo analizado que el nuestro no posee. Una es el sentimiento de que todo lo real es significativo; desde las fuerzas básicas, como la gravitación, hasta la necesidad humana de simbolizar, los resultados resultaban comprensibles. Hoy partimos de una hipótesis distinta: la realidad es como es sin tenernos en cuenta; podemos comprenderla, pero no se «creó» con el deseo de expresar o comunicar. La ciencia ha avanzado con esto, pero el mundo se ha deshumanizado y perdido su simbolismo. Otra es la comprensión integral de la realidad que proporcionaba. Todo era fuerza y forma, aquélla diversificada de la gravedad al pensamiento, ésta de la geometría planetaria a la sintaxis del lenguaje. Toda esta variedad cabía dentro de un esquema global que permitía respetar su diversidad e integrarla en una unidad de significado, algo que hoy no nos permitimos hacer.

Eso fue posible gracias, en parte, al uso del rostro humano como metáfora. No es que los autores pensaran que la historia o las plantas eran iguales que él, sino que por su especial significado podía ser usado como forma en la que inspirarse al organizar los saberes. Ha habido teóricos de la ciencia que han defendido el pensamiento metafórico en la investigación científica. ${ }^{107}$ Nuestra comparación con la época estudiada permite comprender que, desechada la metáfora del rostro, no hemos dado con otra adecuada y que, fuera cual fuera, los desarrollos posteriores tendrían que mantener matices de la misma, como en el caso tratado, donde se mantuvo el sentido expresivo en cada disciplina. No era antropomorfismo, sino el sentimiento de que en este mundo no estábamos como extraños, sino en nuestra casa, entre seres que nos eran familiares.

105 Wölfflin, H., Renacimiento y Barroco, Barcelona, Paidós, 1991, pp. 80-96; Simmel, G., El individuo y la libertad, Barcelona, Península, 2001, pp. 283-292 y Simmel, G., Rembrandt, Murcia, COAAT, 1996, pp. 7-102; Spengler, O., La decadencia de Occidente, Vol. 1, Madrid, Espasa-Calpe, 1993, pp. 137-161.

106 Carus, C. G., Cartas y anotaciones sobre la pintura de paisaje, Madrid, Visor, 1992, pp. 160-170; Darwin, Ch., La expresión de las emociones, Pamplona, Laetoli, 2009; Lorenz, K., Consideraciones sobre las conductas animal y humana, Barcelona, Plaza \& Janes, 1976, pp. 29-33.

107 Brown, T. L., Making Truth. Metaphor in Science, Illinois, University of Illinois, 2003, pp. 30-54. 
